Article

\title{
Social Project Culture: A New Project Management Culture to Promote the Sustainable Development of Organizations
}

\author{
Hailing Wang ${ }^{1}$, Libiao Bai ${ }^{1, * \mathbb{C}}$, Ning Huang ${ }^{1}$, Qiang Du ${ }^{1} \mathbb{C}$ and Tingting Zhang ${ }^{2}$ \\ 1 School of Economics and Management, Chang'an University, Middle Section of South Second Ring Road, \\ Xi'an 710064, China; hailing711@163.com (H.W.); Ning_Huang@chd.edu.cn (N.H.); q.du@chd.edu.cn (Q.D.) \\ 2 School of Civil Engineering, Chang'an University, 161 Middle Chang'an Road, Xi'an 710061, China; \\ 2015128079@chd.edu.cn \\ * Correspondence: LB.Bai@chd.edu.cn; Tel.: +86-29-8233-9228
}

Received: 28 November 2018; Accepted: 25 December 2018; Published: 3 January 2019

\begin{abstract}
With economic development and globalization, more organizations have been cooperating with foreign enterprises, which brings not only opportunities but also management difficulties and competitions with organizations. Organizations must improve their management and adapt to changing market conditions and the requirements and needs of its customers to maintain and strengthen its position in the market. Management by Project (MBP) uses technical methods of modern project management (PM) to manage various tasks and activities that are considered as projects. It is an effective way to solve management problems and improve management levels and enterprise competitiveness. However, few small and medium-sized enterprises apply MBP in their operation and management processes. Therefore, this paper presents a new idea to promote the application of MBP and the formation of a PM culture within society. In this paper, we searched a major database using the systematic literature review method and analyzed the articles directly or indirectly linked to our paper to obtain literature supporting the views of this article. First, this paper presents a new kind of management culture from the social aspect, termed as Social Project Culture (SPC), which can promote sustainable development and improve the management level and efficiency of organizations by promoting MBP application across society. Second, by analyzing the SPC definition, its three functions, i.e., project management behavior, management and risk control capacity, and international competitiveness, are provided. Then, to help organizations apply this method, an evolutionary path is proposed, including the creation stage, formative stage, mature stage, and heritage stage. Finally, to ensure the continued optimization of SPC, four safeguard measures in terms of theory, institution, behavior, and ideology are proposed.
\end{abstract}

Keywords: social project culture; management by project; evolution path; sustainable development

\section{Introduction}

With economic development and globalization, more organizations have been cooperating with foreign enterprises, which brings not only opportunities but also management difficulties and competitions with organizations. Organizations must improve their management and adapt to changing market conditions and the requirements and needs of its customers to maintain and strengthen its position in the market. Therefore, organizations are striving to improve their management and competitiveness in order to promote sustainable development.

To deal with an increasingly complex business environment, organizations have begun to find new methods to improve management ability and solve management problems, such as transformation and 
upgrading issues, risk control, and self-management problems [1]. Hence, the idea of Management by Project (MBP), which leads to clearer management purposes, more scientific control, and more efficient operation results [2], is proposed to solve the management problem and promote the sustainable development of organizations and enterprises.

However, at present, the organizations utilizing MBP are mostly large corporations. Few small and medium-sized enterprises implement MBP into their operational processes [3]. Many management problems, such as transformation and upgrading issues, risk control, and self-management problems, are becoming key impediments to the sustainable development of these enterprises, which plays an irreplaceable role in promoting economic development [4-6]. Therefore, it is imperative to find a way to generalize the MBP concept to improve the management capacity of small and medium-sized enterprises and promote the sustainable development of organizations [7-9].

Based on the management problems of small and medium-sized enterprises and a systematic literature review of papers directly or indirectly linked to culture and PM such as MBP, studies on enterprise project culture (EPC) and organizational culture, this paper proposed a new kind of management culture, termed Social Project Culture (SPC). The aim of SPC is to help organizations, especially small and medium-sized enterprises, achieve sustainable development by improving the application of MBP in society. It can then also indirectly promote economic development through the prosperity of organizations and enterprises.

The definition and functions of SPC are provided to make the leaders of relevant organizations clearly understand its connection. We describe the evolution of SPC to guide users in implementing SPC and help them to make this culture more suitable for their socio-economic environment. Meanwhile, to ensure the smooth implementation and continued optimization of SPC, four safeguard measures in terms of theory, institution, behavior, and ideology are proposed. These guarantees can also reduce the risk of implementation and ensure the formation of SPC.

This paper is structured as follows. Section 2 describes the literature review. The methodology is introduced in Section 3. Section 4 elaborates on the connotation of SPC and presents an analysis of the important role of SPC. Section 5 addresses the four stages of SPC's evolutionary path. The four safeguard measures from theory, systems, behavior, and ideology are provided in Section 6 . Conclusions and discussions are drawn in Section 7.

\section{Literature Review}

Modern project management (PM), especially the idea of MBP, has become popular within organizations [10-12]. As a modern model, MBP uses technical methods of modern PM to manage various tasks and activities that are considered as projects [13,14], and is an effective method to improve the efficiency of enterprise management $[10,15,16]$. The concept of MBP was first advanced in the mid-1980s [17] and applied in a number of areas, such as architecture, national defense, aerospace, etc. After the 1990s, MBP was gradually applied to the rapidly developing IT industry and other high-tech fields [18], which effectively improved management ability in these fields. As a result, more and more enterprises and departments chose to complete their work using MBP [19]. Since then, MBP has been used in multi-project management, including project program and project portfolio management, and become the main management model in organizations due to its advantages in pursuing organizations' strategies, improving resource utilization, and solving sustainable development problems [20,21]. Above all, most researchers concentrate on how to apply it in different fields and the optimization of this theory. Few researchers pay attention to promoting the application of this method within society for sustainable development of organizations, especially small and medium-sized enterprises. There are also few studies that combine MBP and culture. In order to fill these research gaps, SPC is proposed to guide organizations, especially small and medium-sized enterprises, to achieve sustainable development by promoting the application of MBP within society.

Culture is typically viewed as the values, beliefs, and ideology of an organization or society [22-24]. It influences the way in which people behave $[25,26]$. A person's decision-making process is dependent 
on their cultural background according to what is considered 'the right way', highlighting the importance of culture [27]. As a collection of group consciousnesses, the guiding role of culture in society has become increasingly prominent [28,29], especially in the management of enterprises and organizations [30-32]. Therefore, theoretical research focusing on cultural perspectives has significantly improved in the field of management [33-35]. Some researchers have pointed out that PM culture is enterprise-oriented [7,36-41]. It is considered as a unique culture within a project or a project portfolio. They have also analyzed its importance in the success and sustainable development of projects [42,43], especially cross-border international cooperation projects [44-47]. Other researchers have noted that PM culture is a set of stable beliefs, attitudes, and values recognized from the perspective of an enterprise, and could combine the values of members with strategic objectives to promote the realization of those objectives [48]. Drawing conclusions from this previous research, it can be argued that PM culture is only suitable for spreading MBP within enterprises and not suitable for prompting the application of MBP within society. Therefore, we propose SPC from a social perspective for the first time. It fills the research gap in that most researchers only concentrated on management culture from the perspective of a single enterprise.

\section{Methodology}

In our analysis we make use of the systematic literature review (SLR) approach. The SLR method originated in the 1990s, and it was initially used in the field of medicine, although more recently it has also been adopted in various fields, such as systems engineering, marketing, tourism, and strategic innovation [49-52]. We reviewed the literature directly or indirectly linked to culture, organizational culture, enterprise project culture, and project management. Some of the references we selected to support the viewpoint of this paper are summarized in Appendices A and B, the others are described in this paper. The systematic review process is presented as follows.

\subsection{Search Strategy}

SLR was conducted as a research methodology to collect material for this paper. To obtain the relevant literature, we used a search in the common database of published literature including Web of Science, Springerlink, Wiley Online Library, Elsevier and China National Knowledge Infrastructure, one of the largest biomedical abstracts and full test literature databases in China. In addition, references identified from bibliographies of pertinent articles were also retrieved if needed. We made no restriction on language or date. The searches sought the following combinations of key words: "management by project", "project management", "enterprise project culture", "enterprise culture", "organizational culture", "culture", "enterprise culture AND function", "culture AND function", "enterprise culture AND evolution", and "culture AND evolution".

\subsection{Criteria}

The studies are selected to support the conception provided in this paper. Therefore, articles were included when they met the following criteria:

1. The paper included the key words that we mentioned above.

2. The definition of enterprise project culture or culture is provided in the paper.

3. The function of project management, management by project, enterprise project culture or organizational culture, or culture is described directly or indirectly.

4. The evolution of enterprise project culture or culture is decribed.

\subsection{Study Selection}

First, we selected the studies based on titles, key words, and abstracts of the retrieved records. Studies that did not meet the criteria were discarded during the initial review. Then, we cross-checked these studies. When uncertainty existed, we retrieved and assessed the full text studies if they were 
available. Different opinions were resolved through discussion. The articles we selected have been cited in this paper. The views of the articles we referenced to support this paper have been summarized in Appendices A and B.

\section{Overview of Social Project Culture}

\subsection{Connotation of Social Project Culture}

Culture is a type of social phenomenon based on a certain organization and produced in a certain environment [53]. It is an internal restriction and norm, which is widely recognized by humans in social activities. Culture can guide the public and organizations to choose their own behavior to achieve long-term, sustainable development [42,53]. SPC is a special kind of culture that emerges during the process of popularization and application of PM in various fields. The benefit of promoting SPC to realize organizations' long-term sustainable development is obvious [54]. However, the definition of SPC has not been determined. Therefore, it is necessary to define SPC in order to promote it.

SPC has a strong similarity in several aspects with enterprise-based group consciousness-enterprise project culture (EPC). Both SPC and EPC attempt to popularize $\mathrm{MBP}$ and build a project culture to ensure sustainable development and achieve organization strategic objectives with the MBP application. Hence, it can be concluded that the EPC characteristics can provide a reference for defining SPC [55], which enables SPC to be analyzed from three aspects, i.e., scope, purpose, and result, and the definition of SPC can be described as follows.

Definition: SPC is a consensus that originates from the MBP process. It is composed of PM values, management styles, management methods, and ideological systems, of which the purpose is to improve the efficiency of management activities and guide the organization to form management behavior and achieve sustainable development.

The number of cooperative projects is increasing and the scale is expanding, which brings difficulties to organizations. SPC can contribute to solving this problem. SPC helps guide organizations to conduct activities using PM in order to improve the management efficiency of organizations and ensure the smooth implementation of cooperation. Its purpose is to guide enterprises, individuals, and outreach groups to address cooperative matters using project management. It will promote the success of a single project into the success of the organization, and the success of a single organization into the success of national strategy. Eventually, a kind of project management value concept, system standard, management thought, and management behavior are formed.

The connotation of SPC is complicated; it involves many influencing factors, such as project environment, national policy, and management capacity, which cause difficulties for building SPC in essence [54]. Similar to the process of forming corporate culture [56] and EPC, the core elements in building SPC are the scope, purpose, and result [54,57]. Therefore, in this paper, the connotation of SPC is described as follows: from the scope perspective, the scope of SPC is covered by the whole organizations in society. From the perspective of construction purpose, the main purpose of building SPC is to guide the organization to apply PM to its daily routine. Based on the result analysis, SPC adapts to the special background of the society to form PM values, concepts, system standards, management ideas, and management behaviors for organizations.

\subsection{Functions of Social Project Culture}

Based on analyzing the previous studies, we found that as a special kind of management culture SPC has functions in culture as well as PM [54]. Here, the functions in culture are orientation, value integration, and normative integration, which will guide the organization to achieve sustainable development. Developing a corporate culture supersedes factors such as corporate strategy, market presence, and technological advantage to affect the success of a company [58]. The functions in PM work towards more flexible organizations, closer teamwork, and a more efficient management process [2]. According to the method we described in Section 3, we selected some literature to support 
the function provided in this section, as summarized in Appendix A. The functions of SPC can be concluded by combining the functions of culture and $\mathrm{PM}$, which can be divided into three aspects, as shown in Figure 1 [59-66].

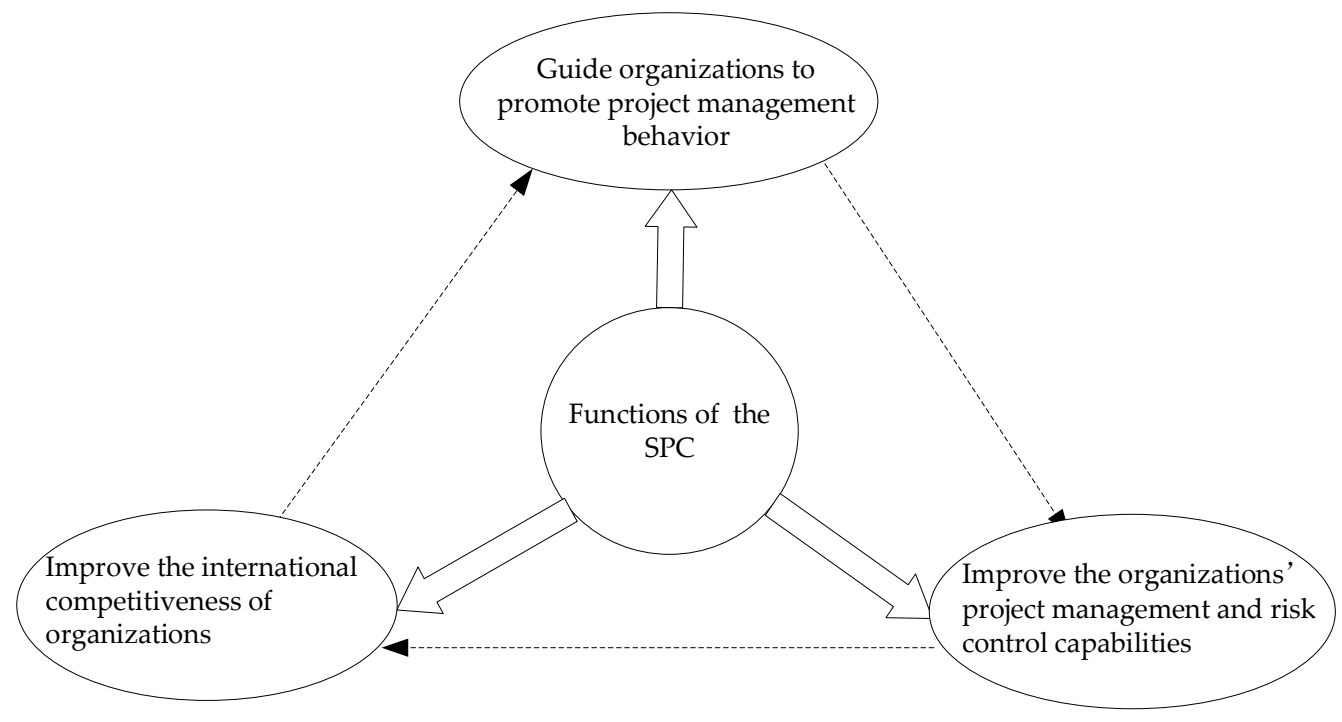

Figure 1. Functions of Social Project Culture (SPC).

Figure 1 shows that guiding organizations to promote PM behavior and sustainable development is the primary function of SPC. SPC emphasizes PM behavior implementation, PM system establishment, and PM thinking formation during the MBP process. It guides organizations, individuals, and groups to address affairs, actualize PM behavior, and manage using a specific program in accordance with the MBP principles, which will promote their sustainable development.

The second function of SPC is to help organizations improve their PM and risk control capabilities (Figure 1). Modern PM emphasizes three-dimensional constraints (quality, cost, and duration) as well as other factors, such as human, risk, and flexible management. Hence, the establishment of an intangible mechanism is required to ensure PM implementation and integrate the rigid and flexible constraints. In addition, SPC could ensure that organizations perform activities in accordance with MBP and control risks by using systematic procedure in the order of plan, organize, implement, control, and finish.

The importance of SPC can be reflected in improving the third function of SPC, i.e., international competitiveness of organizations, individuals, and groups (Figure 1) by facilitating enterprises to apply MBP. Within the MBP trend, building SPC will help organizations, individuals, and groups improve their levels of technical services, engineering quality, and management [7-9]. Ultimately, these organizations will achieve a market advantage with higher efficiency and quality and raise their international and sustainable development competitiveness.

It can be found that these three functions correlate with each other and can work together to improve the management level of the company for sustainable development. In practice, SPC will help organizations develop PM behavior, which will in turn improve the organizations' PM and risk control capability, management efficiency, and international competitiveness. Hence, more organizations will be encouraged to develop PM behavior.

\section{Evolutionary Path of Social Project Culture}

With the implementation of policies such as "The Belt and Road", the number of cross-border projects has increased, which provides a broader space for the practice of project management. Modern project management not only requires the support of all kinds of 'hardware' but the assistance of 'software' such as project management culture. Therefore, the development process of SPC should 
be included, in addition to building SPC. At present, there are few studies about the evolutionary path of SPC, but many researchers have studied similar corporate culture. By analyzing the existing literature shown in Appendix B, it can be found that the development of culture generally includes four stages: generation, interpretation, identification, and following [67-73]. As a management culture, SPC includes some other complex processes, such as creation, formation, improvement, and heritability. Therefore, the evolutionary path of SPC can be constructed in four steps: cultural creation, cultural formative, cultural maturity, and cultural heritage, as shown in Figure 2.

According to the evolutionary path of SPC shown in Figure 2, first, government departments, PM institutes, or other organizations create SPC based on the environment of society and enterprises. Then a special PM agency is established by a PM institution or the relevant government departments to establish and improve the PM rules and regulations. After that, these relevant departments guide managers to apply MBP and PM knowledge in their organizations. Through the successful implementation of individual project management, the idea of PM is gradually extended to the whole industry. It then extends to multiple industry areas. The concept of project management is deepened and SPC is initially formed within society. Then, relevant organizations evaluate the effect of the implementation of SPC and propose some optimization measures to make it more suitable for the current social and economic environment. SPC is recognized generally and constantly inherited. The specific implementation method of each stage is as follows.

The creation stage, as the first evolutionary phase of SPC, refers to how to build SPC based on the environment of society and enterprises to improve the adaptive capacity. At the beginning of this stage, the idea of PM is proposed and promoted by government departments, PM institutes, or other organizations. Then, the basic framework of SPC is proposed after analyzing the construction environment, the construction content, the construction purpose, the target group, etc. The requirements for creating the SPC should be raised and used to guide the subsequent building stage.

The second evolutionary phase of SPC is the formative stage, referring to how to make society accept and implement SPC. This is a process that makes SPC convert from concept to behavior and mainly includes three parts: (1) Identifying SPC. In the initial construction stage, some employees may doubt the SPC functions, and hence some methods, such as publicity, training, and communication, are adopted to help them accept and recognize SPC and provide ideological guarantees for the implementation of specific actions. (2) Implementing SPC. The SPC will be translated into practical action from the level of managers' design frame in the implementation process. (3) Building SPC. The purpose of building SPC is to promote MBP and guide people to form PM behavior. The project management organizations (PMOs), as direct users of SPC, could regulate people's will and behavior and make sure they follow and implement what the SPC advocates. In order to ensure that SPC can be implemented in a mandatory manner, institutionalizing PM and building SPC systematically are necessary. 


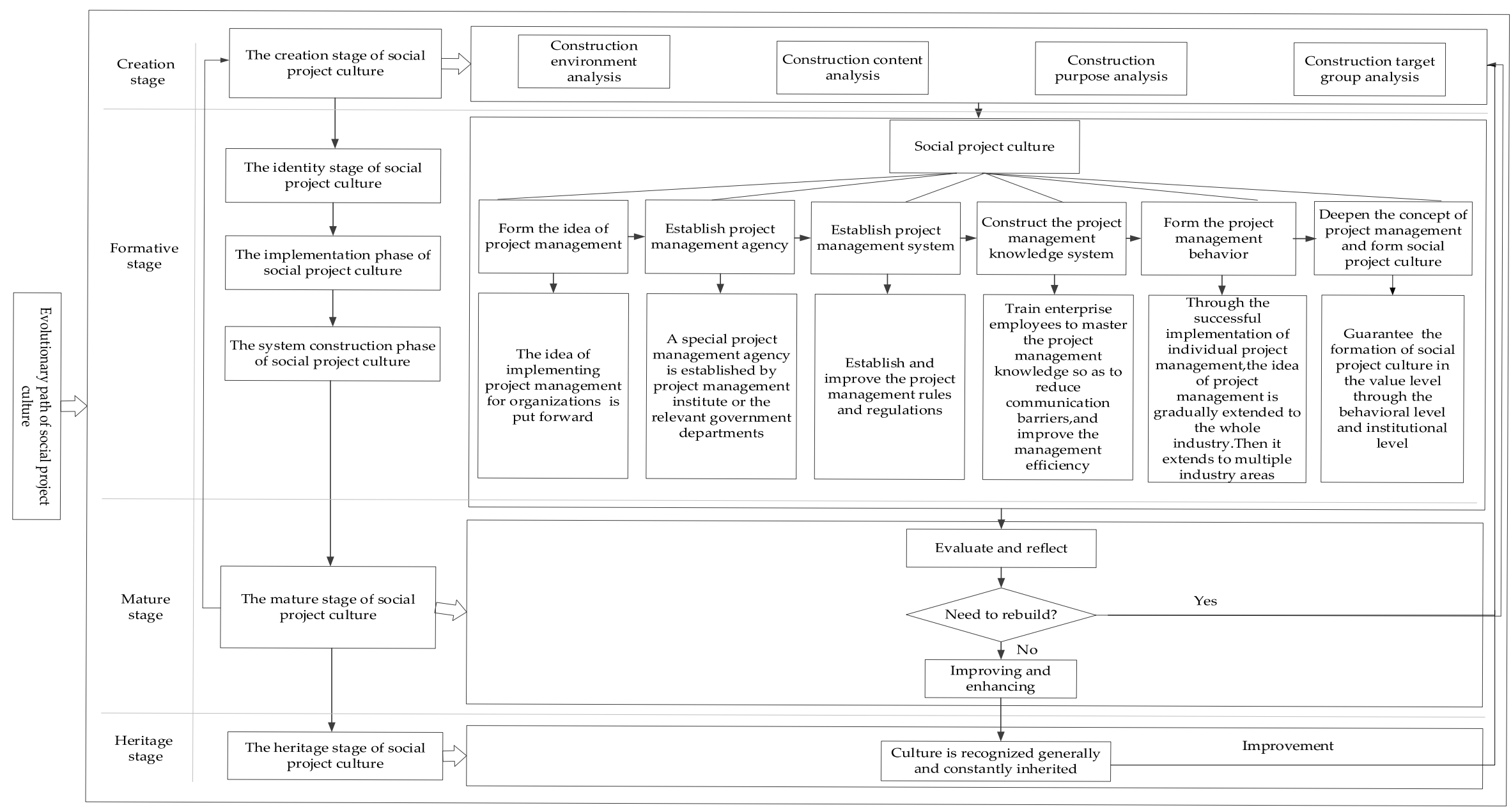

Figure 2. Evolutionary path of SPC. 
The process of the SPC formative stage is shown in Figure 2. First, according to the actual situation of a project, a PM idea based on SPC is proposed. Then, a PM agency is established by an institution or a relevant government department responsible for developing and designing standards of PM, which provides guidance for project activities and deploys and builds the SPC. PM institutions or government legal branches regulate the management process and the division of responsibilities by establishing the relevant PM system. After that, the PM system can ensure PM process standardization, define the division of responsibilities clearly, and restrain the behavior of project members, while the management system helps the organization ensure that the PM procedure is working correctly and the activities are efficiently managed, which will provide an institutional guarantee for SPC construction. Finally, PM agencies or organizations could carry out some training and experience exchange activities to help employees understand, master, and apply PM knowledge. These steps would lay the foundation for developing PM behavior, reducing communication barriers, and improving management efficiency. After summarizing the successful experience in an individual organization, the MBP application can be gradually extended to the entire industry, and the MBP behaviors could evolve from a single project to a complex program or project portfolio management, which provides a guarantee for building the SPC and promoting the sustainable development of the organization. During the formative stage of SPC, a foundation for raising people's awareness of MBP and promoting SPC development is established. However, during the formation process of SPC, the order of multi-subprocesses is not fixed. It should be noted that these subprocesses could begin simultaneously as long as the conditions required for building the culture are satisfied.

The third evolutionary phase of SPC is the mature stage, referring to evaluation and improvement. The original SPC may contain many shortcomings, so evaluating and analyzing the SPC insufficiency from PM systems, PM departments, PM practices, and other aspects is an effective way to realize SPC's sustainable improvement. Through this assessment, the basic situation of the established SPC can be grasped, on the basis of which suggestions for sustainable improvement can be proposed. If the evaluation results reflect that the original SPC cannot fulfill the requirements for building the culture, the process of building the SPC will be reorganized or returned to the first stage. If the evaluation results show that the initial SPC satisfies the requirements for building the culture but is insufficient, the shortcomings will be addressed. Afterwards, the SPC is re-evaluated to ensure that the purpose of the organization's sustainable development can be achieved. It can be seen that during the formative stage and mature stage, SPC can be accepted by staff and workers, optimized, and applied in different organizations, and then management can be guided to improve the success rate of projects.

The fourth evolutionary phase of SPC is the heritage stage, referring to how to inherit and develop the SPC. Similar to the final step of constructing a culture, building SPC eventually realizes the development and heritance of the ideas, theories, and methods of MBP in organizations to guide organizations to achieve sustainable development in contemporary society.

\section{Guarantees for Promoting Social Project Culture}

The evolutionary process of culture can be influenced by the social environment. At present, some problems in the social environment obstruct SPC evolution, such as lack of awareness of PM [74], insufficient attention of leaders paid to PM [75], and inadequate systems built for PM [76]. Solving these problems is a prerequisite for building the SPC, but it is a complex process involving many disciplines, such as organizational ecology $[77,78]$, management $[7,9,14]$, and organizational management [79]. Therefore, considering the existing literature in different disciplines, this paper proposes four supporting guarantees (i.e., theoretic guarantee, behavior guarantee, institutional guarantee, and ideological guarantee) in order to solve the problems for confirming the realization of SPC (Figure 3), which are elucidated as follows. 


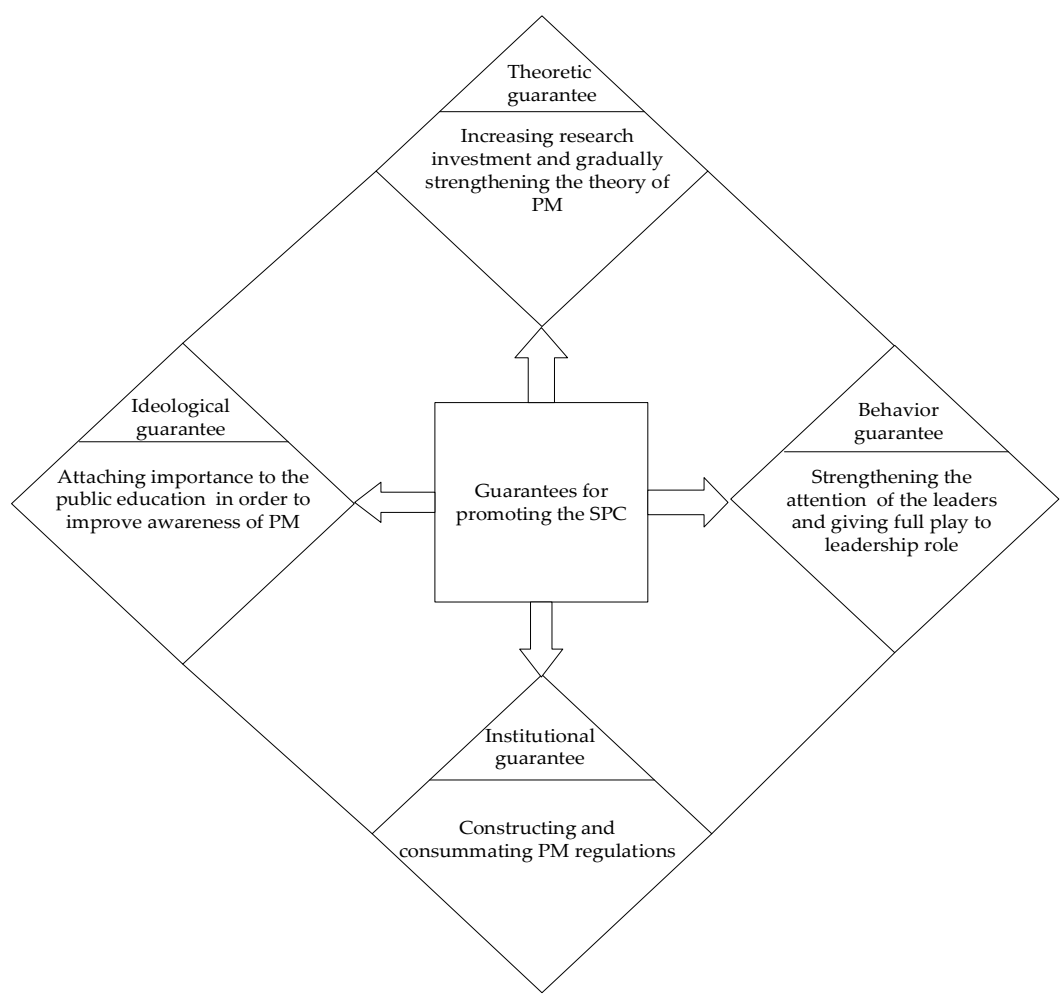

Figure 3. Guarantees for promoting the SPC.

The SPC is a combination of project management ideas and culture, so it is imperative to strengthen the theory of MBP for the continuous optimization of this theory. Theoretic guarantee is the basis of promoting SPC from a theoretical perspective. Therefore, it is important to propose this guarantee. There are many approaches to providing theoretical guarantees for the realization of SPC. For example, talent support for SPC implementation can be supplied by developing the academic and vocational education of PM. As a system that provides comprehensive theoretical support for PM practice, PM science can be established to adapt to the requirements of this new trend [80] with some corresponding and supporting policies formulated by the relevant government departments, PM institutions, research institutions, or other organizations. Investment in PM theory and the study of PM science is required to provide a theoretical basis for an organization to carry out PM activities, especially for modern projects that are becoming more variable, uncertain, complex, and ambiguous.

The behavior guarantee is provided to instruct people's behavior during the implementation process. It is key to building SPC to help top managers pay sufficient attention to PM. The behavior patterns and values of senior managers determine which culture the organization pursues. Leaders should pay attention to PM implementation. As behaviors of cultural construction leaders, such as government departments and PM associations, tend to set an example for employees, they must fulfill their responsibility as cultural leaders and demonstrate the important role of PM in production practice for employees through their own actions. In this way, a powerful guarantee is provided for SPC development.

Institutional guarantee is another important support for the construction of SPC to solve the problem of inadequate system building for MBP. In addition, it can prompt the formation of SPC by constraining and guiding people's behavior during the implementation process. A unified PM system can guarantee PM quality, regulate behavior rationality, and ensure the systematic implementation of SPC to adapt to the special trends of MBP. For instance, the PM system could help organizations, individuals, and groups apply the theory of MBP in practice. This system can provide a standard specification of PM that allows different organizations to explore personalized management combined with their characteristics and finally achieve the ultimate goals: improving 
the efficiency of PM, enhancing the organization's competitiveness, and achieving the sustainable development of the organization.

Social project culture has both management characteristics and cultural characteristics. It not only affects people from the mind but also influences them from behavior. Therefore, as a special kind of culture, it is imperative to provide ideological guarantees to ensure that people form this kind of thinking. The fourth guarantee, the ideological guarantee, is the core of building SPC. Attaching great importance to publicity and education and improving the awareness of project management in enterprises, individuals and groups provide the ideological guarantee for constructing SPC.As is known, the main body in the process of culture building is people. If there is no effective participation from the people, the culture is just a facade. At present, different people have different understandings of PM, which has hindered the implementation of PM. Therefore, it is necessary to strengthen publicity and education for personnel and improve their technical quality, cultural quality, and moral quality, which will provide an ideological basis for SPC construction. For this purpose, government departments and PM associations should carry out a variety of PM-related training activities to encourage outreach enterprises, individuals, and groups to pay attention to PM. Consequently, an organization's PM skills can be improved and PM ideology can form, which will lay a foundation for the implementation of PM behavior and make construction of the SPC possible.

\section{Conclusions and Discussion}

Under the background of 'The Belt and Road', the number of collaborative projects is increasing, and the background of the stakeholders involved in the projects is also becoming more complex. This situation requires pursuing win-win modern project management to meet the needs of management. Modern project management pays more attention to the market and competition, focusing on the human factor. It ensures projects are carried out efficiently with its systematic management theory and methods. Therefore, the idea of constructing SPC in Chinese society is proposed. Its purpose is to guide outreach organizations to apply the concept of MBP to their practical management activities. The importance of constructing social project management is analyzed. Then, the evolution path of SPC is built within the context of 'The Belt and Road'. Finally, some corresponding safeguard measures are proposed. This provides a new idea for promoting the extensive application of project management, with details shown as follows.

With the number of collaborative projects increasing, the background of the stakeholders involved in the projects is also becoming more complex. Modern PM, taking into consideration influencing factors such as competitions and markets, is a win-win PM strategy that can satisfy sustainable development requirements. As a modern model, MBP uses technical methods of modern PM to manage various tasks and activities that are considered as projects and is an effective method to improve the efficiency of enterprise management [10,13-16]. MBP promotes cooperation among different projects and organizations and can accelerate economic development. With this approach, all projects can be executed efficiently based on the application of a systematic management theory, method, and culture. In this paper, SPC, which aims to achieve the sustainable development of organizations by guiding employees to apply MBP and practical management activities in society, has been proposed. Its evolutionary path including four stages has also been described. Moreover, in order to ensure that SPC is accepted, used, and promoted by the organization, some corresponding safeguard measures have been proposed.

SPC is a type of consensus which is formed in the process of implementing the idea of project management in society. As a special form of culture, SPC not only has the function of culture but also the characteristics of PM mode. On the one hand, culture has the functions of orientation, value integration, normative integration, and so on. On the other hand, a project management model can make organization management more flexible, teams work more closely, and management process more efficient. Culture has a strong influence on people, which will lead the members of society to choose certain behavior. SPC emphasizes implementation of project management behavior, 
establishment of the project management system, and formation of project management thinking during the implementation. Therefore, when SPC is formed, it will lead the members of society to choose behavior according to this cultural background. It will instruct enterprises, individuals, and groups to address affairs, to actualize project management behavior, and to manage with a specific program in accordance with the ideas of MBP. We summarize some of the benefits of this culture as follows.

For organizations, SPC can improve their management efficiency and management capacity. In addition, it can reduce the communication barriers in different enterprises and improve the success rate of cooperation. For managers, SPC can reduce the management difficulties caused by different cultures, outdated management, and changing environments. For government, it can indirectly promote the economic development of society by prompting the prosperity of enterprises and organizations.

Finally, this study provides a new idea for the sustainable development of organizations by promoting the extensive application of MBP innovations shown as follows:

1. Combined with the MBP trend, the SPC concept is proposed, which defines the concept of PM culture at the social level. Furthermore, the important role of SPC is analyzed, and a new field regarding PM culture at the social level is provided from the perspective of organizations.

2. Referring to the established literature, the evolutionary path of SPC is constructed based on four stages of culture: creation, formation, maturity, and inheritance. With this evolutionary path of SPC, the requirements of building a culture from four aspects (i.e., materials, behaviors, systems, and spirits) can be satisfied.

3. According to the social status of PM, some safeguard measures are proposed from the aspects of theory, system, behavior, and ideology. At the theoretical level, investment in PM research should be increased, and a disciplined system for projects should be created and improved. At the system level, the corresponding PM system should be established and improved, and the leaders should pay more attention to SPC construction and take an active role as cultural leaders at the behavioral level. At the ideological level, PM should be given great importance in publicity and education to improve the PM ideology of organizations, individuals, and groups. The combination of these four guarantees ensures the realization of SPC and sustainable development of organizations.

There are two shortcomings in this study: (1) In this paper, we proposed a general framework of the evolutionary path of SPC roughly, and the specific details require in-depth analysis. (2) The proposed evolutionary path of SPC is a general framework, which needs an in-depth analysis for specific cases in actual practice. These limitations will be addressed in future research.

Author Contributions: All authors contributed equally to this work. All authors wrote, reviewed and commented on the manuscript. All authors have read and approved the final manuscript.

Funding: This research is supported by the National Natural Science Foundation of China (No. 71802003), Ministry of Education Humanities and Social Sciences Fund (No. 17XJC630001), Soft Science Foundation of Shaanxi Province (No. 2017KRM123), Social Science Planning Fund of Shaanxi Province (No. 2017S028), Social Science Planning Fund of Xi'an (Nos. 17J173, 18Z49) and the Fundamental Research Funds for the Central Universities (Nos. 300102238620, 300102238303).

Conflicts of Interest: The authors declare no conflict of interest. 


\section{Appendix A}

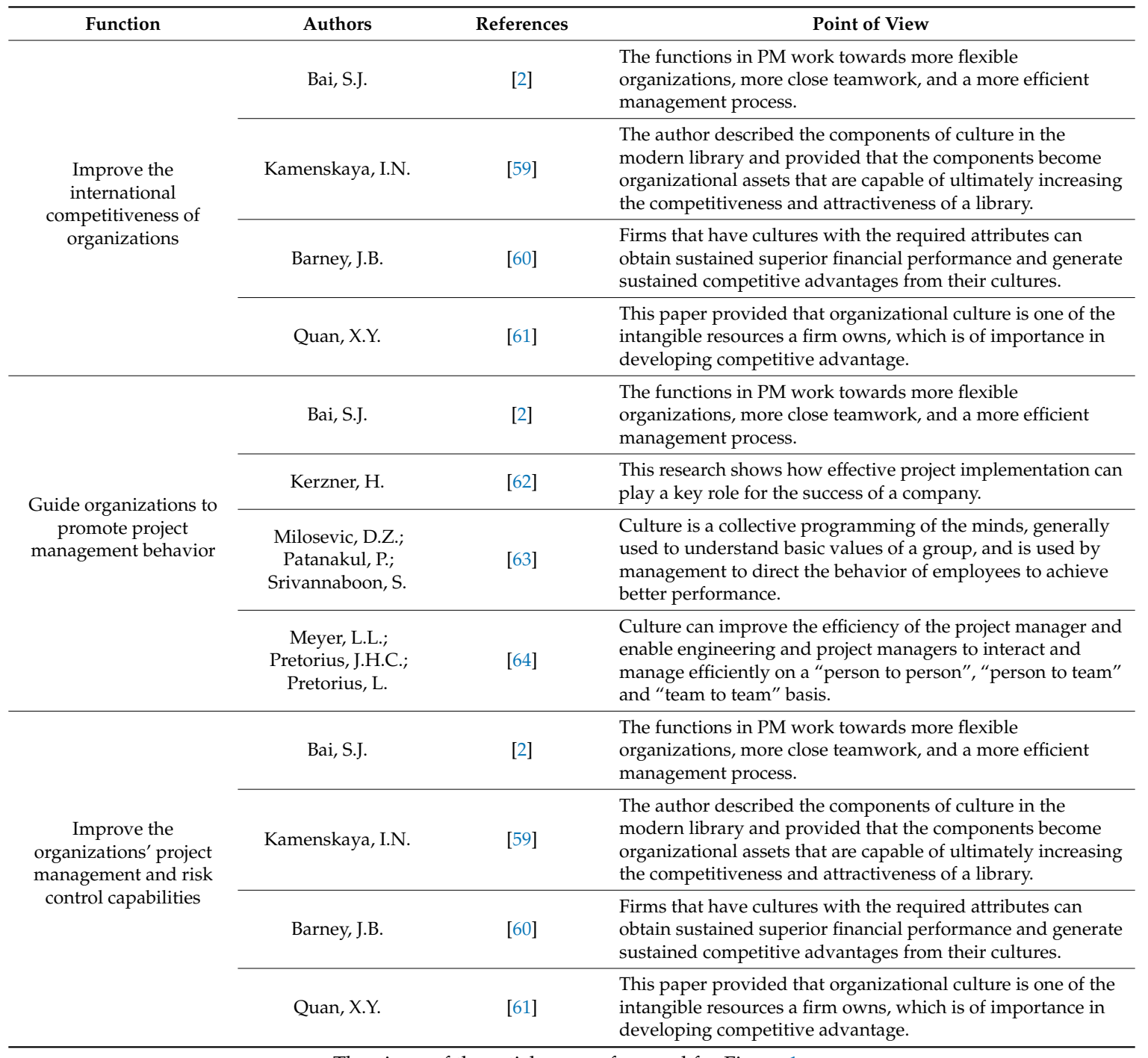

The views of the articles we referenced for Figure 1. 


\section{Appendix B}

\begin{tabular}{|c|c|c|}
\hline Authors & References & Point of View \\
\hline Schein, E.H. & [67] & $\begin{array}{l}\text { The formulation of corporate culture must consider the economic and social } \\
\text { environment in which the company is located. }\end{array}$ \\
\hline $\begin{array}{l}\text { Conbere, J.P.; } \\
\text { Heorhiadi, A. }\end{array}$ & [68]. & $\begin{array}{l}\text { The construction of corporate culture should be considered in the construction of } \\
\text { corporate culture. The behavior of leaders has an important influence on the } \\
\text { implementation of culture. }\end{array}$ \\
\hline Fan, G.Y. & [69] & $\begin{array}{l}\text { The formation process of corporate culture includes the following processes: } \\
\text { 1. Creating the corporate culture: Corporate leaders build their own cultural based } \\
\text { on the enterprise characteristics and social environment. } \\
\text { 2. Accept the corporate culture: Let the employees of the company understand and } \\
\text { agree with the culture of the company. } \\
\text { 3. Behavioral training: Train employees to work in accordance with the culture of } \\
\text { the company. } \\
\text { 4. Support for stability of corporate culture: Through various measures to ensure } \\
\text { the inheritance and continuity of corporate culture. }\end{array}$ \\
\hline Wang, W.K. & [70] & $\begin{array}{l}\text { The formation process of corporate culture includes the following processes: } \\
\text { 1. The leader proposes the cultural concept. } \\
\text { 2. Corporate managers practice culture and strengthen the implementation of } \\
\text { the culture. } \\
\text { 3. People implement the organization's culture in the company. }\end{array}$ \\
\hline Wang, S.J. & [71] & $\begin{array}{l}\text { 1. Analyze the external environmental conditions and the strategy of the } \\
\text { corporates, Form the cultural mechanism of the enterprise, including the cultural } \\
\text { control mechanism and inheritance mechanism. Form the unique corporate } \\
\text { environment and employee behavior culture of the enterprise. }\end{array}$ \\
\hline Rose, K.H. & [72] & $\begin{array}{l}\text { Organization culture is shaped by the common experience of the organization and } \\
\text { most organization have developed unique cultures over time by practice and common } \\
\text { usage. Common experience include, but not limited to: shared vision, mission, values, } \\
\text { beliefs and expectation } \\
\text { 1. regulations, polices, methods, and procedures } \\
\text { 2. motivation and reward systems } \\
\text { 3. risk tolerance } \\
\text { 4. view of leadership, hierarchy, and authority relationship } \\
\text { 5. code of conduct, work ethic, and work hours } \\
6 . \quad \text { operating environment }\end{array}$ \\
\hline Palmer, M. & [73] & $\begin{array}{l}\text { Establishing a project culture } \\
\text { 1. initiate the project: formalize the initiation of project } \\
\text { 2. project definition } \\
\text { 3. analysis of the issues } \\
\text { 4. developing a European project process } \\
\text { 5. launch and roll-out } \\
\text { 6. review }\end{array}$ \\
\hline
\end{tabular}

The views of the articles we referenced for Figure 2.

\section{References}

1. Bu, X.L. Thinking about 'going out' engineering contracting within the context of 'The Belt and Road'. Macroecon. Manag. 2016, 2, 57-60.

2. Bai, S.J. Modern Project Management; China Machine Press: Beijing, China, 2010; ISBN 978-7-111-10090-5.

3. Gang, L. The application of project management in small and medium-sized enterprises. New Economy 2016, 12, 103-104.

4. Hai, B.W. The Strategic Work of Small and Medium Enterprises on China's Economic Development. Spec. Zone Econ. 2010, 12, 234-235.

5. Shun, F.A. The Impact of Developing Small and Medium Enterprises on China's Economy. Times Finance 2013, 24, 170 .

6. Xin, L. China's economic development and the role of Small and Medium Enterprises. Bus. Res. 2012, 4, 189-190.

7. Bai, L.B.; Du, Q. Co-evolution efficiency of project portfolio based on strategic orientation. Rairo-Oper. Res. 2017, 52, 645-659. [CrossRef]

8. Xue, M.Z.; Ran, L. The project management of enterprises. Econ. Tribune 2006, 3, 81-83. [CrossRef] 
9. Gareis, R. Management by projects: The management strategy of the 'new' project-oriented company. Int. J. Proj. Manag. 1991, 9, 71-76. [CrossRef]

10. Maylor, H.; Brady, T.; Cookedavies, T.; Hodgson, D. From projectification to programmification. Int. J. Proj. Manag. 2006, 24, 663-674. [CrossRef]

11. Kerzner, H. Implementation of Project Management; Project Management Case Studies; Wiley-Blackwell: Hoboken, NJ, USA, 2017.

12. Turner, R.; Ledwith, A. Project Management in Small to Medium-Sized Enterprises: Fitting the Practices to the Needs of the Firm to Deliver Benefit. J. Small Bus. Manag. 2016, 56, 475-479. [CrossRef]

13. Dan, W.D.; Qing, L.L. Research on Enterprise Project by Management Mode. J. Manag. Case Stud. 2013, 26, 163-168.

14. Gareis, R. 'Management by projects': The management approach for the future. Int. J. Proj. Manag. 1989, 7, 243-249. [CrossRef]

15. Chen, X.F. Research on the Construction and Promotion of Project Management System of BC Company. Zhejiang University of Technology: Zhejiang, China, 2014.

16. Winter, M.; Smith, C.; Cooke-Davies, T.; Cicmil, S. The importance of 'process' in Rethinking Project Management: The story of a UK Government-funded research network. Int. J. Proj. Manag. 2006, 24, 650-662. [CrossRef]

17. Sharad, D. Management by projects-an ideological breakthrough. Proj. Manag. J. 1986, 3, 61-63.

18. Xie, L.N. Research on Cultural Characteristics of Project Management in IT Project. Master of Thesis, Yunnan University, Yunnan, China, 2010.

19. Winter, M.; Szczepanek, T. Projects and programmes as value creation processes: A new perspective and some practical implications. Int. J. Proj. Manag. 2008, 26, 95-103. [CrossRef]

20. Davidovitch, N.; Belichenko, M.; Kravchenko, Y. Information Resources Usage in Project Management Digital Learning System. J. Educ. Learn. 2017, 6, 146. [CrossRef]

21. Kivilä, J.; Martinsuo, M.; Vuorinen, L. Sustainable project management through project control in infrastructure projects. Int. J. Proj. Manag. 2017, 35. [CrossRef]

22. Dimaggio, P. Culture and cognition. Metaphilosophy 1997, 23, 263-287. [CrossRef]

23. Montobon, F.; Pagell, M.; Wu, Z. Making Sustainability Sustainable. J. Supply Chain Manag. 2016, 52, 11-27. [CrossRef]

24. Song, F.; Montabon, F.; Xu, Y. The impact of national culture on corporate adoption of environmental management practices and their effectiveness. Int. J. Prod. Econ. 2018, 205, 313-328. [CrossRef]

25. Mintu, A.T. Cultures and Organizations: Software of the Mind. J. Int. Bus. Stud. 1992, 23, 362-365. [CrossRef]

26. Alkhoraif, A.; Mclaughlin, P. Lean implementation within manufacturing SMEs in Saudi Arabia: Organizational culture aspects. J. King Saud Univ.-Eng. Sci. 2018. [CrossRef]

27. Podrug, N. Influence of national culture on decision-making style. South East. Eur. J. Econ. Bus. 2011, 6, 37-44. [CrossRef]

28. Sacco, P.L.; Ferilli, G.; Tavano Blessi, G. From Culture 1.0 to Culture 3.0: Three Socio-Technical Regimes of Social and Economic Value Creation through Culture, and Their Impact on European Cohesion Policies. Sustainability 2018, 10, 3923. [CrossRef]

29. Wróblewski, Ł.; Dziadzia, B.; Dacko-Pikiewicz, Z. Sustainable Management of the Offer of Cultural Institutions in the Cross-Border Market for Cultural Services-Barriers and Conditions. Sustainability 2018, 10, 3253. [CrossRef]

30. Firth, G.; Krut, R. Introducing a project management culture. Eur. Manag. J. 1991, 9, 437-443. [CrossRef]

31. Eberlein, M. Culture as a critical success factor for successful global project management in multi-national it service projects. J. Inf. Technol. Manag. 2008, 19, 27-42.

32. Morrison, J.M.; Brown, C.J.; Smit, E.V.D.M. The impact of organizational culture on project management in matrix organizations. S. Afr. J. Bus. Manag. 2008, 39, 27-36.

33. Henrie, ME.; Sousa-Posa, A. Project management: A cultural literary review. Proj. Manag. Inst. 2005. [CrossRef]

34. Maya, I.; Rahimi, M.; Meshkati, N.; Madabushi, D.; Pope, K.; Schulte, M. Cultural Influence on the Implementation of Lessons Learned in Project Management. EMJ-Eng. Manag. J. 2005, 17, 17-24. [CrossRef]

35. Zhang, Y.; Marquis, C.; Filippov, S.; Haasnoot, H.J.; Martijn, V.D.S. The Challenges and Enhancing Opportunities of Global Project Management: Evidence from Chinese and Dutch Cross-Cultural Project Management. Soc. Sci. Electr. Publ. 2015, 15. [CrossRef] 
36. Yazici, H.J. The role of project management maturity and organizational culture in perceived performance. Proj. Manag. J. 2010, 40, 14-33. [CrossRef]

37. Daneshka, A. On the cultural profile of project management, Ikonomiceski i Sotsialni Alternativi. Available online: https:/ /ideas.repec.org/a/nwe/iisabg/y2016i3p83-92.html (accessed on 17 December 2018).

38. Hajian, H.; Astani, S. A Research Outlook for Real-Time Project Information Management by Integrating Advanced Field Data Acquisition Systems and Building Information Modeling. In Proceedings of the Computing in Civil Engineering, Austin, TX, USA, 24-27 June 2009.

39. Yuan, D.; Sai, Y. The Research on System of Construction Materials Management by Project. In Proceedings of the International Conference on Management and Service Science, Wuhan, China, 24-26 August 2010; pp. 1-4.

40. Ou, L.X.; Yu, W.M. Strategic Programme Selection Model for Enterprise Management by Project. Sci. Technol. Eng. 2007, 7, 2182-2186.

41. Wei, Y.; Miraglia, S. Organizational culture and knowledge transfer in project-based organizations: Theoretical insights from a Chinese construction firm. Int. J. Proj. Manag. 2017, 35, 571-585. [CrossRef]

42. Anderson, D.K.; Merna, T. Project management strategy_Project management represented as a process based set of management domains and the consequences for project management strategy. Int. J. Proj. Manag. 2003, 21, 387-393. [CrossRef]

43. Yan, X.L.; Cao, H.P. Establishment and Realization of Project Culture during the Construction Project Management in China. In Proceedings of the International Conference on Management and Service Science, Wuhan, China, 12-14 August 2011; pp. 1-4.

44. Tsekhovoy, A.F.; Nekrassova, N.A.; Karmazina, L.I. The project management culture: International lessons and kazakhstan's experience. PM World J. 2014, 3, 1-14.

45. Agnantounkpatin, A.R.; Zhang, L.Y. A Framework for Culture Management in Sino-African International Construction Projects. International Conference on Information Management. Innov. Manag. Ind. Eng. 2011, 2, 51-54. [CrossRef]

46. Fish, A. Assisting cross-border manager adjustment: Psycho-cultural and socio-cultural interventions. Pers. Rev. 2005, 34, 225-245. [CrossRef]

47. Shore, B.; Cross, B.J. Exploring the role of national culture in the management of large-scale international science projects. Int. J. Proj. Manag. 2005, 23, 55-64. [CrossRef]

48. Cheng, D.Q.; Chen, K. Organizational project management culture. Proj. Manag. Technol. 2006, 2, 31-35. [CrossRef]

49. Lee, C.K.; Yiu, T.W.; Cheung, S.O. Selection and use of Alternative Dispute Resolution (ADR) in construction Projects-Past and future research. Int. J. Proj. Manag. 2016, 34, 494-507. [CrossRef]

50. Putthiwanit, C. Exploring the Impact of Organizational Culture on Employees in Multinational Enterprise: A Qualitative Approach. Procedia-Soc. Behav. Sci. 2015, 207, 483-491. [CrossRef]

51. Ke, Y.; Wang, S.Q.; Chan, A.P.C.; Cheung, E. Research Trend of Public-Private Partnership in Construction Journals. J. Constr. Eng. Manag. 2009, 135, 1076-1086. [CrossRef]

52. Yu, Y.; Chan, A.P.C.; Chen, C.; Darko, A. Critical Risk Factors of Transnational Public-Private Partnership Projects: Literature Review. J. Infrastruct. Syst. 2018, 24. [CrossRef]

53. Kotter, J.P.; Heskett, J.L.; Li, X.T. Corporate Culture and Performance; China Renmin University Press: Beijing, China, 2004.

54. Zhang, T.T.; Lai, Y.X.; Bai, L.B.; Bai, S.J. Social Project Culture and Its Evolutionary Path. Proj. Manag. Technol. 2017, 15, 7-14. [CrossRef]

55. Zeng, Y.; Jin, M.; Guo, C.; Zhang, Z. Research on evaluation of enterprise project culture based on Denison model. J. Ind. Eng. Manag. 2015, 8, 909-927. [CrossRef]

56. Heng, W.; Yang, D. The theoretical formation process of innovative corporate culture. Mita Bus. Rev. 2007, 50, 385-395.

57. Ajmal, M.M.; Koskinen, K.U. Knowledge transfer in project-based organizations: An organizational culture perspective. Proj. Manag. J. 2008, 39, 7-15. [CrossRef]

58. Arditi, D.; Nayak, S.; Damci, A. Effect of organizational culture on delay in construction. Int. J. Proj. Manag. 2017, 2, 136-147. [CrossRef]

59. Kamenskaya, I.N. Organizational culture as a basis for the competitiveness of a library. Sci. Tech. Inf. Process. 2011, 38, 27-33. [CrossRef] 
60. Barney, J.B. Organizational culture: Can it be a source of sustained competitive advantage? Acad. Manag. Rev. 1986, 11, 656-665. [CrossRef]

61. Quan, X.Y. Exploring Sustained Competitive Advantage: The Effect of Organizational Culture on Firm Performance. In Proceedings of the International Conference on Management Science and Engineering, Chengdu, China, 14-21 July 2007; pp. 1372-1377.

62. Kerzner, H. Culture. In Project Management Best Practices; John Wiley \& Sons, Inc.: Hoboken, NJ, USA, 2014; pp. 335-373.

63. Milosevic, D.Z.; Patanakul, P.; Srivannaboon, S. Cultural Aspects of Project Management. In Case Studies in Project, Program, and Organizational Project Management; John Wiley \& Sons, Inc.: Hoboken, NJ, USA, 2010; pp. 19-27.

64. Meyer, L.L.; Pretorius, J.H.C.; Pretorius, L. Effects of culture on project management contributing to the success of managing culturally diverse engineering teams in a global environment. In Proceedings of the IEEE International Conference on Industrial Engineering and Engineering Management, Bali, Indonesia, 4-7 December 2016; pp. 640-645.

65. Riley, J. Understanding the Antecedent Competencies of Organizational Risk Management Capabilities. Doctor of Thesis, Clemson University, Clemson, SC, USA, 2013.

66. Kimbrough, R.L.; Componation, P.J. The Relationship between Organizational Culture and Enterprise Risk Management. Eng. Manag. J. 2009, 21, 18-26. [CrossRef]

67. Schein, E.H. Culture: The missing concept in organization studies. Adm. Sci. Q. 1996, 41, 229-240. [CrossRef]

68. Conbere, J.P.; Heorhiadi, A. Cultural influences and conflict in organizational change in new entrepreneurial organizations in Ukraine. Int. J. Confl. Manag. 2006, 17, 226-241. [CrossRef]

69. Fan, G.Y. Enterprise Culture's New Definition and the Enterprise Culture Management Model. East China Econ. Manag. 2009, 23, 121-126.

70. Wang, W.K. The Formation Mechanism and Construction Method of Enterprise Culture. Prod. Res. 2009, 5, 251-252.

71. Wang, S.J. Field Research on Enterprise Culture Evolutionary path and Influence on its Performance-The Analysis from the Perspective of Business Anthropology. J. Shanxi Univ. Finance Econ. 2015, 37, 71-84.

72. Rose, K.H. A Guide to the Project Management Body of Knowledge (PMBOK ${ }^{\circledR}$; Guide)—Fifth Edition. Proj. Manag. J. 2013, 44, e1. [CrossRef]

73. Palmer, M. How an effective project culture can help to achieve business success: Establishing a project culture in Kimberly-Clark Europe. Ind. Commer. Train. 2002, 34, 101-105. [CrossRef]

74. Wei, C.L. Discussion on Project Management as a New Direction for the Development of Business Management. J. Harbin Univ. Commerce (Soc. ScienceEdition) 2011, 1, 35-38. [CrossRef]

75. Wang, J.P. Analysis on the Problems and Improvement of Enterprise Project Culture Management. China High.-Tech. Organ. 2016, 20, 169-170. [CrossRef]

76. Li, S.; Yu, Z.H.; Ding, Z.B. The present situation and problems of project management in China. Shanxi Arch. 2008, 8, 229-230. [CrossRef]

77. Hannan, M.T.; Freeman, J.H. Organizational Ecology. Ann. Rev. Sociol. 1984, 10, 71-93. [CrossRef]

78. Boone, C.; Wezel, F.C.; Witteloostuijn, A.V. Top management team composition and organizational ecology: A nested hierarchical selection theory of team reproduction and organizational diversity. Adv. Strateg. Manag. A 2006, 46, 97-124. [CrossRef]

79. Wood, R.; Bandura, A. Social Cognitive Theory of Organizational Management. Acad. Manag. Rev. 1989, 14, 361-384. [CrossRef]

80. Qian, F.P. The Call of the Times-on the Establishment of 'Project Science'. In Proceedings of the 2016 China Project Management Conference and International Forum on Chinese Characteristics and Cross-Cultural Project Management, Xi'an China, 26-27 November 2016.

(C) 2019 by the authors. Licensee MDPI, Basel, Switzerland. This article is an open access article distributed under the terms and conditions of the Creative Commons Attribution (CC BY) license (http:/ / creativecommons.org/licenses/by/4.0/). 